ALPHA No 29 Diciembre 2009 (251-268)

ISSN 0716-4254

http://alpha.ulagos.cl

\title{
ACERCA DE LA FUNCIÓN EMANCIPATORIA Y EL ESTATUTO CRÍTICO DE LA INTERPRETACIÓN EN PSICOANÁLISIS
}

About its emancipatory function and the status of interpretation in critical psychoanalysis

Niklas Bornhauser*

Resumen

El psicoanálisis es una práctica plural, múltiple y abierta. Su diálogo con otras disciplinas no solamente constituye una contribución relevante al debate público contemporáneo, sino que se torna en exigencia indispensable en cuanto a su devenir como discurso interesado en librarse de la tutela o servidumbre con respecto a los saberes establecidos.

En este artículo se aborda el ejercicio del psicoanálisis ligado a la práctica crítica en su sentido estricto, función crítica asociada a la correspondiente concepción de interpretación y a la práctica interpretativa que se vuelve posible a partir de ella. En la medida en que la interpretación se pretenda reveladora, conlleva la necesidad de problematizar las relaciones de poder que la condicionan y contextualizan, por lo mismo, en este análisis se postula que una ética psicoanalítica debe considerar estos elementos en la medida en que quiera efectuar una contribución al debate contemporáneo y, en particular, al proyecto emancipador del cual forma parte.

Palabras clave: Crítica, interpretación, poder, ética.

Abstract

Psychoanalysis is a plural, multiple and open practice. Its dialogue with other disciplines not only constitutes a relevant contribution to the present public debate, but is an indispensable exigency towards its own future as a discourse interested in getting rid of the trusteeship or servitude of established knowledge.

In that sense, the exercise of psychoanalysis is bound to the critical practice in its strict sense. This critical function is associated to the corresponding conception of interpretation and the respective interpretative practice. Interpretation, insofar as it pretends to be truly revealing, entails the necessity to promote a judicious analysis of the relations of power that condition and contextualize it. A psychoanalytical ethics must consider these elements if it wants to make a contribution to the contemporary debate and particularly to the emancipatory project of which it is part.

Key words: Critique, interpretation, power, ethics. 


\section{Niklas Bornhauser}

\section{INTRODUCCIÓN}

El psicoanálisis, desde sus orígenes, es una disciplina híbrida, plural y heterogénea. En su constante reformulación convergen un número de prácticas diversas y desemejantes, que se fecundan y repelen recíprocamente; entre ellas, en primer lugar, la filosofía, la psiquiatría, la antropología y la lingüística.

En la medida en que el psicoanálisis - concebido como una estructura abierta - se distingue de todo sistema cerrado del pensar, su devenir en el siglo XXI depende de su capacidad de someter sus antecedentes, sus influencias y sus derivaciones a un análisis histórico y racional, es decir, de escribir su propia historia conceptual (Begriffsgeschichte) (Koselleck, 1979; Gumbrecht, 2006). No obstante, además de lo anterior, los rumbos abiertos a partir de su respectivo diagnóstico del presente se juegan en su solvencia a la hora de contribuir al cuestionamiento de la comprensibilidad de suyo (Selbstverständlichkeit) del statu quo y de proponer alternativas, cualitativamente diferentes, a los modos establecidos de pensar y hacer.

El logro de dicho desafío, a saber, el de pensar de otra manera, se supedita, entre otros, a su disposición a revisar el lugar que ocupa en el conjunto orquestado de prácticas y quehaceres - científicos- que distinguen el panorama actual y de esclarecer, en la medida de lo posible, su correspondiente "disciplinary matrix" (Kuhn, 1970:182) con tal de favorecer su aspiración hacia la "mayoría de edad” (Mündigkeit) en un sentido ilustrado (Kant, 1784).

La discusión pormenorizada tanto de la raigambre -histórica, científica, política, etc.- de sus conceptos y de los principios y supuestos que animan y orientan su práctica forma parte de un esfuerzo disciplinar, sostenido por un interés cognoscitivo emancipatorio que apunta, la autorreflexión mediante, a desatarlo de la dependencia de poderes hipostasiados y establecerlo como teoría y práctica crítica (Habermas, 1968).

En relación a lo anterior, la hipótesis que se quiere poner a prueba es la siguiente: existe una determinada "propiedad" del psicoanálisis, que es coextensiva tanto a su teoría como a su práctica, a saber, su dimensión crítica. Esta dimensión se encuentra estrechamente vinculada a su correspondiente concepción de interpretación. Desde un punto de vista que provisoriamente se llamará epistemológico ya se puede adelantar que el derrotero de aquella facultad crítica dependerá, entre otros, de su capacidad de problematizar las relaciones de poder-saber existentes y de trazar alternativas viables a los modos establecidos de hacer, prescritos por la doxa hegemónica. 
Acerca de la función emancipatoria y el estatuto crítico de la interpretación

\section{ACTITUD CRÍTICA Y EPISTEME PSICOANALÍTICA}

Actualmente, cuando en el habla cotidiana (Alltagssprache) se emplea el término "crítico", se hace en el sentido de "una situación o un estado crítico", por ejemplo, tal como uno lo hace al hablar de "un paciente crítico". En ese sentido, un estado crítico es toda aquella situación clínica en la que el paciente tiene o puede tener severamente alteradas una o más constantes vitales, ya sea por un periodo de tiempo determinado o indeterminado.

Designar algo como crítico equivale a decir que algo debe ser objeto de particular atención, pues "no marcha bien". Generalmente connota la preocupación por lo precario, frágil, tenue o perecedero de un objeto - 0 varios- cuya existencia está puesta en riesgo. De este modo, cuando en el deporte, digamos, por ejemplo, en el fútbol, se recurre a dicha expresión, habitualmente ello expresa un estado de ánimo que va desde la nerviosidad hasta el desasosiego por el pasado, presente o futuro - ya sea deportivo o económico- del equipo en el cual están puestas las ilusiones del hincha o del fanático en cuestión.

Se podría inferir, por ende, que el calificativo "crítico" se encuentra vinculado, de una manera, que aún cabe precisar, al menos en el habla ordinaria, a la persistencia de "las cosas" y a la pregunta por sus condiciones de existencia. Efectivamente, partiendo del análisis del habla rutinario y corriente, uno, en principio, podría colegir que lo crítico se relaciona con una cierta amenaza, un peligro de fin, de término o de disolución. Sería, por consiguiente, una señal de amenaza; más específicamente, del peligro de muerte inminente que arroja anticipatoriamente sus sombras sobre el presente, correspondiéndose, por ende, hasta cierto punto, con una señal de angustia, que advierte acerca de la inminencia del peligro de expiración y muerte.

La crítica des-substantivada, en tanto actitud o quehacer, se asemeja a un instrumento que opera sobre un cierto dominio, estableciendo, de este modo, una distancia (Friedeburg y Habermas, 1983) y, en un segundo paso, una cierta perspectiva (Butler, 2002) sobre las formas de conocimiento establecidas y ordenadoras.

A partir de lo expuesto se desprende la exigencia que todo pensamiento -incluso, o ante todo, el pensamiento cuestionador - requiere develar y examinar las formas de justificación de su propia aproximación. Al respecto, Foucault en L'archéologie du savoir ha argumentado que el pensamiento tiene no solamente la libertad sino, incluso, el deber de tomar una perspectiva crítica respecto de su propia constitución, quitándole a las “cosas” y, más importante aún, a sí mismo, su engañosa familiaridad.

El psicoanálisis, tal como corrobora la siguiente referencia a Freud, con respecto a esto no constituye una excepción 


\section{Niklas Bornhauser}

Muchas veces hemos oído sostener el reclamo de que una ciencia debe construirse sobre conceptos básicos (Grundbegriffe) claros y definidos con precisión. En realidad, ninguna, ni aun la más exacta, empieza con tales definiciones. El comienzo correcto de la actividad científica consiste más bien en describir fenómenos que luego son agrupados, ordenados e insertados en conexiones. Ya para la descripción misma es inevitable aplicar al material ciertas ideas abstractas que se recogieron de alguna otra parte, no de la sola experiencia nueva. Y más insoslayables todavía son esas ideas - los posteriores conceptos básicos de la ciencia - en el ulterior tratamiento del material. Al principio deben comportar cierto grado de indeterminación (Unbestimmtheit); no puede pensarse en ceñir con claridad su contenido (1915:109).

La crítica, en tanto Kritik que se distingue de la mera Krittelei, chismorreo, rezongo o murmullo, equivale a una forma del pensar que se interroga no solamente por las condiciones, sino por los límites de los más seguros y asegurados modos de conocimiento. Estas modalidades afianzadas de pensar, que propician la difusión de lo que R. Williams (1976) designó justamente como los "hábitos mentales acríticos”, establecen la división entre lo pensable y lo no-pensable, bloqueando la irrupción de lo no-deseable, en otras palabras, precisamente aquello que tiene que ver con la dimensión inconsciente del deseo, con lo que el acontecimiento tiene de aleatorio e imprevisible. La promoción de ciertos términos instrumentales, aquello que T. W. Adorno (1962) designó como operationale Begriffe, una vez establecidos como referentes inamovibles del lenguaje dominante, se convierte en el principal obstáculo para que la crítica opere como parte de una "práctica material" que apunte a captar los modos como las propias categorías se instituyen. ${ }^{1}$ El objeto de la crítica, por decirlo de algún modo, sería la manera

\footnotetext{
${ }^{1}$ La alusión a Adorno, en el contexto de este trabajo, es de carácter ilustrativo y tangencial y, a diferencia de lo que sucede con Habermas, en ningún caso constituye una referencia teórica imprescindible para el desarrollo del argumento central. Como es consabido, mientras que los trabajos del primero se inscriben, principal aunque no exclusivamente, en el análisis del nazismo, el estudio de la sociedad post-industrial y sus estructuras sociopolíticas y culturales, efectuando - junto a Max Horkheimer y Herbert Marcuse - un sólido aporte teórico y metodológico a la llamada Teoría Crítica clásica, Jürgen Habermas, en cambio, pertenece a lo que ha sido distinguido como segunda generación compuesta, principalmente, además de él, por Claus Offe, Oscar Negt, Alfred Schmidt y Albrecht Wellmer. Cfr. Rolf Wiggershaus. Die Frankfurter Schule. Geschichte —Theoretische Entwicklung - politische Bedeutung. München/Wien: Carl Hanser Verlag (1986). Con respecto a la obra de Jürgen Habermas, la recepción contemporánea (Jay, 1973; McCarthy, 1978) distingue una primera etapa, en la cual aún sigue, muy directamente, los planteamientos de la teoría crítica según Horkheimer y Adorno, de una segunda, en la cual renueva esta misma, manteniendo la perspectiva de oposición al cientificismo positivista y de intento de transformación de la sociedad mediante la reflexión crítica, apoyándose —más que en la tradición idealista— en la nueva filosofía del
} 
como se ordena el campo de saber, cómo se efectúa la oclusión constituyente de ciertos dominios especializados y cómo, en un segundo momento, lo que este campo suprime mediante el cierre del universo discursivo (Marcuse, 1964) retorna.

Se encuentran antecedentes de este ejercicio que develan las limitaciones de las perspectivas disciplinarias y apuntan a cuestionar las categorías filosóficas utilizadas habitualmente con tal de reafirmar una determinada visión-de-mundo (Weltanschauung) en los escritos freudianos, particularmente en la $35^{\mathrm{a}}$ de las Nuevas conferencias de introducción al psicoanálisis (1933-1932), titulada precisamente “Über eine Weltanschauung”. Dicho estilo corrosivo del pensar, que devela el encubrimiento o el conveniente olvido de ciertas verdades incómodas — tal como lo fue, en su momento, el descubrimiento de la sexualidad infantil- inscribe a Freud entre los llamados maestros de la sospecha (Ricoeur, 1965). Empero, el pensamiento freudiano no se detiene ahí, en el mero develamiento o desocultamiento, sino que procede a interrogar las formas discursivas hegemónicas, establecidas precisamente sobre dicha supresión, con lo cual el psicoanálisis se funda y se deshace en las mismas fronteras del pensar.

En palabras de Judith Butler, "no se trata de referir la práctica a un contexto epistemológico dado de antemano, sino de establecer la crítica como la práctica que cabalmente expone los límites de ese mismo horizonte epistemológico, haciendo que los contornos del horizonte, por así decir, aparezcan puestos en relación con su propio límite por vez primera” (2002: 218).

En efecto, la actitud crítica llevó la práctica clínica más allá de sus fronteras designadas, ya que Freud la aplicaría a expresiones psíquicas antaño descartadas como manifestaciones insensatas, carentes de sentido. Con ello disolvió los vínculos de univocidad, supuestamente existentes entre la cara visible de los síntomas y la significación, inscribiendo al psicoanálisis en la senda de un proyecto crítico que "parece conducido por naturaleza, por

lenguaje. Sin adherir por completo a esta división, nos parece altamente aclaratoria con relación al distanciamiento de sus formulaciones teóricas respecto a los planteamientos de $\mathrm{T}$. W. Adorno. Las posibilidades de emancipación del hombre contemporáneo, por ende, se vinculan estrechamente con el ejercicio de la crítica, en particular la crítica de las ideologías — ciencia y técnica, en primer lugar- y de la manera como se establezca, por ejemplo, el recurso al psicoanálisis. A su vez, la relación entre teoría y práctica, que se aleja de las concepciones (neo)positivistas actuales, se vincula con el análisis de la relación entre las diversas formas de conocimiento y los diferentes intereses convergentes, sentando de este modo las bases para que la crítica de la sociedad supere el mero comprender y se traduzca en los esfuerzos de liberación de las variadas y cada vez más sofisticadas formas de dominación. 


\section{Niklas Bornhauser}

función, diría que por profesión, a la dispersión, a la dependencia, a la pura heteronomía” (Foucault, 2006:4).

La crítica, "no existe más que en relación con otra cosa distinta a ella misma”, reitera Foucault (2006:5). En ese sentido, la crítica es siempre crítica de algo: de una práctica, de un discurso, de una institución.

La actitud crítica, de acuerdo con lo anterior, se constituye en y mediante su oposición a la inapelable autoridad de las formaciones ideológicas institucionalizadas, contraponiéndose al reinado indefectible de la comprensibilidad de suyo, al dominio ciego e irrebatible del llamado sentido común. En el caso de Freud, el psicoanálisis se constituyó como una genuina crítica del sentido común, tal como consta en sus problemas (Figueroa, 2007), sus textos (Rozitchner, 1987) e, incluso, en el mismo estilo de Freud (Mahony, 1982).

En este punto, más allá de sus respectivas diferencias, hay cierta coincidencia entre Freud y Gramsci, ya que el segundo concibe a la filosofía como "la crítica y la superación de la religión y del sentido común; entendida de este modo, coincide con el 'buen sentido', que se contrapone al sentido común” (Gramsci, 1972:15). En efecto, el pensamiento de Freud se encuentra con el marxismo de Gramsci en la medida en que ambos estarían de acuerdo en que "una filosofía de la praxis no puede dejar de presentarse inicialmente como una actitud polémica y crítica, como superación del modo de pensar precedente y del pensamiento concreto existente (o del mundo cultural existente). Es decir, debe presentarse ante todo como crítica del "sentido común” (Gramsci, 1972:21).

La senda del psicoanálisis pasa, entonces, por la recuperación de esta vocación irrecusablemente crítica; esta disposición, incondicional e intransable, a refutar el carácter autoritario y coercitivo de los modos establecidos de pensar.

Se podría decir, con respecto al psicoanálisis, que "a diferencia de esa correspondencia e inteligibilidad entre palabra y mundo, entre palabra conceptual y realidad, que había sido casi un dato intrínseco a la filosofía de la Modernidad, filosofía científica, filosofías racionalistas, filosofías positivistas, nos encontramos con una ruptura, con un quiebre del contrato, con una suerte de dispersión del sentido" (Forster, 1999:128).

La renuncia al pensamiento único implica, asimismo, no solamente aceptar la imposibilidad de hablar de un psicoanálisis, entraña, asimismo, el cuestionar y refutar la deseabilidad de dicha ilusión. Prescindir de las aspiraciones a constituirse al modo de un metarécit (Lyotard, 1979) permite concebir al psicoanálisis como una conformación amalgamada y transitoria, que se compone a partir de la combinatoria entre dominios singulares y puntuales. Por consiguiente, las relaciones entre el psicoanálisis y otras prácticas, establecidas a partir de situaciones y contextos determinados, serán 
mucho más contingentes, circunstanciales y parciales de lo que cualquier aspiración totalizante pueda hacer pensar.

\section{TEORÍA Y PRÁCTICA PSICOANALÍTICA: LA INTERPRETACIÓN}

En la medida en que el psicoanálisis se reconoce a sí mismo como producción policéntrica, insurgente e insurrecta —que no necesita, para afirmar su validez, del beneplácito de los poderes amos- se torna posible distinguir un conjunto articulado de microteorías, de formulaciones teóricas microscópicas, citológicas, confinadas a dominios circunscritos y particulares. Es el caso de la teoría de la seducción, la teoría del trauma, la teoría de las neurosis e, incluso, de la llamada metapsicología, para nombrar solamente a algunas formaciones teóricas locales y situadas. Se trata, en cada caso, de formulaciones preliminares y contingentes que responden a problemas puntuales y precisos, inscritos en contextos históricos particulares, tanto de la época como de la obra de Freud, acotados en cuanto a sus correspondientes contornos o recintos teóricos (Grubrich-Simitis, 1993).

La práctica psicoanalítica, cuyas aspiraciones emancipatorias son irrenunciables — al menos en la medida en que se pretenda heredera de la ambición ilustrada de inspiración freudiana (Pohlen y Bautz-Holzherr, 2001) en lugar de una entidad compacta, monolítica e impenetrable- es un agregado híbrido y múltiple, conformado por un complejo entramado de conexiones de reciprocidad que van de un punto teórico a otro. Convergen en la práctica del psicoanálisis elementos teóricos disímiles y dispares, procedentes de diferentes disciplinas —fisiología, filosofía, incluso ciertos precedentes de una especie de teoría cultural incipiente, etc. (Bercherie, 1983) - y, entre los cuales, se establece todo tipo de nexos, enlaces y ligaduras. Es, precisamente, debido a esta pluralidad irreductible que se pueden proyectar relaciones diversas y variables con diferentes disciplinas y prácticas discursivas, no necesariamente emparentadas; al menos, en principio.

Al mismo tiempo, la teoría psicoanalítica, en tanto conformación heterogénea y compuesta, puede ser pensada como los empalmes y ensambladuras de una práctica con otra. Dichas articulaciones no se dan, al menos no exclusivamente, al modo de síntesis, integraciones y acoplamientos, sino que, al tratarse de relaciones entre fuerzas, se producen también $-\mathrm{y}$ de manera determinante- a través de desencuentros, colisiones y choques. ${ }^{2}$

2 Avances y retrocesos, ensayos y errores, modelos provisorios, experiencia clínica y autoanálisis, desarrollo de contradicciones entre nociones propias y ajenas, dificultades técnicas impuestas por resistencias (empíricas) de los pacientes o insuficiencias confesadas por el mismo Freud, todo ello marcado por una decisión de no defender una elaboración cuando los hechos muestran sus insuficiencias... (todo ello conforma un) cúmulo de circunstancias 


\section{Niklas Bornhauser}

Freud, a través de su práctica interpretativa, desmonta todo modelo que defina, por un lado, la existencia de un dominio especulativo, teorizante e hipotético —asentado firmemente sobre sus fundamentos epistemológicos consolidados - y, por el otro, la presencia de un ámbito efectivo, expeditivo y práctico. Esta relación ideológica, heredera del neopositivismo imperante, a partir de Freud será reemplazada por algo muy distinto: la idea de un sistema de conexión abierto, incompleto, articulador de una multiplicidad de piezas parciales y fragmentarias, de segmentos a la vez teóricos y prácticos.

La teoría psicoanalítica, por lo tanto, no es que prescriba, exprese o traduzca una práctica: es una práctica. Crítica, práctica e interpretación, en el psicoanálisis, se anudan de la siguiente forma

Toda la riqueza de la noción de praxis está contenida en esta idea de que la interpretación puede ser una herramienta de crítica, de "puesta en crisis" de las estructuras materiales y simbólicas de una sociedad, en polémica con otras interpretaciones que buscan consolidarlas con su inercia (Grüner, 1995:12).

El psicoanálisis, para servirse de la tan manoseada y ajada metáfora foucaultiana, es, por ende, una boîte à outils, una "caja de herramientas" (Deleuze, 1972), un acervo de utensilios, artefactos y artilugios cuya principal relación no es con el registro simbólico, o sea, con el ámbito de la significación. La teoría psicoanalítica, según consta a lo largo de la obra freudiana, es inseparable de la práctica clínica: pero lo es, en particular, de sus desafíos, dificultades e impasses. La simultánea consideración de sus logros y fracasos impone la pregunta por los intereses, las voluntades y los deseos, encarnados en prácticas diferentes y divergentes, que traspasan y sostienen el territorio social.

En lugar de concebirse como una búsqueda objetiva e imparcial, que forma parte de un proyecto neutro y desinteresado - que aspira a ciertos objetivos puramente cognoscitivos - se debe pensar, más bien, en términos de una lógica propia a las relaciones de poder y a las luchas que se establecen alrededor de ellas.

En el caso del psicoanálisis y de su práctica, la cual es una práctica interpretativa (Ricoeur, 1969) resulta inevitable formular la pregunta por su vinculación con el deseo que es, en este caso, un "deseo del texto" (Barthes, 1982). Toda interpretación, por más desapasionada e imparcial que se pretenda, hunde sus raíces en el exuberante suelo pulsional conformado por un

aparentemente desordenadas, organizadas por un trabajo titánico contra la corriente de los lugares comunes de su época (Pasternac, 1975:211). 
caldero en ebullición y, a cambio, recibe de éste su dimensión pasional, hacia la cual debe establecer una relación que pasa por una decisión ética.

El deseo, que en este caso sostiene la interpretación — según Lacanno es deseo de algo, en el sentido de la satisfacción de una necesidad objetiva y concreta o del anhelo de un ente tangible y material, sino que es siempre deseo de un objeto inalcanzable, imposible, desde siempre perdido (Lacan, 1991). El objeto del deseo, por lo tanto —-más que su desenlace o fin- es su causa, dando lugar a un deseo que se configura como deseo de una falta. La interpretación, de acuerdo a lo anterior, lejos de des-(en)cubrir un sentido originario, nativo y primordial —que se halla oculto en estado latenteconverge hacia un punto liminar, excesivo y desmedido que se asemeja a lo que Freud describió como la experiencia de la locura.

Llegar a este punto de no return supone "situarse en el borde mismo de la angustia, tenue límite donde se padece el máximo de desgarramiento y la más extrema vacilación subjetiva” (Milmaniene, 2002:28). A partir de aquí, o bien se asume el riesgo de avanzar sin garantías ni certezas - lo que implica exponerse a las consecuencias impredecibles e ignotas de cualquier acto- 0 bien se desanda el camino avanzado, retrocediendo hacia esa región confusa y brumosa en la cual la inacción y la inhibición frente a lo desconocido se mezclan y confunden con la cobardía. La interpretación psicoanalítica, en la medida en que no cede ante su propio deseo — que, paradójicamente, es siempre deseo de otro - nos llevará siempre a este punto decisivo, en el cual todo lo que uno haga o evite hacer marca un antes y un después, enfrentándonos ineluctablemente con la monumental tarea de plasmar nuestro deseo en la elección de un acto vinculante y responsable.

\section{DISCUSIÓN: CONSIDERACIONES A PROPÓSITO DE UNA ÉTICA PSICOANA- LÍTICA}

Retomando las reflexiones iniciales, la crítica psicoanalítica, al oponerse a la tiranía del sentido único y a la regulación normativa y coercitiva de la práctica, tiene por objeto, distinguido y descollado, la problematización de las relaciones de poder.

Para ello, en primer lugar, se debe impugnar la presunta idealidad y objetividad neutra del saber, pero, asimismo, es necesario denunciar "a otra muy curiosa y muy hipócrita división del trabajo entre los hombres del poder y los hombres del saber, (que) dio lugar a ese curioso personaje, el del sabio, el científico que debe renunciar a cualquier poder, renunciar a cualquier participación en la ciudad, para adquirir la verdad” (Foucault, 1999:155). El psicoanálisis contribuye, sin lugar a dudas, al desenmascaramiento de aquella gran fábula que Occidente, bajo el mito del amor desinteresado al saber, se 


\section{Niklas Bornhauser}

cuenta a sí mismo con el propósito de encubrir su tremenda sed, su colosal apetito de poder.

De este modo, la crítica desde sus orígenes aparece vinculada a la pregunta por las relaciones de poder y, más específicamente, a la pregunta por cómo en toda sociedad - pero en nuestra sociedad, la sociedad disciplinaria, en particular - las diversas relaciones de poder atraviesan, distinguen y constituyen el cuerpo social. El poder, bajo las disposiciones reticulares que va conformando, es coextensivo a todo el cuerpo social y toda práctica se inscribe, inexorablemente, en su tejido relacional. En otras palabras, está siempre ahí, nunca se está fuera de él, no hay márgenes que delimiten un adentro de un afuera (Ewald, 1989).

La pregunta por el poder, en contra de cualquier concepción esencialista, parte del postulado de que "este poder como tal no existe" (Foucault, 1988) y se formula, predominantemente, en términos de su "cómo" es decir, de su actuar, sus mecanismos y sus efectos. Coincide en este aspecto con el inconsciente, al menos en su acepción lacaniana, en tanto "aquella parte del discurso concreto en cuanto transindividual que falta a la disposición del sujeto para restablecer la continuidad de su discurso consciente" (Lacan, 1972).

De manera análoga, el ejercicio del poder, no es que sea reducible a la simple puesta en relación entre diferentes actores sociales, sean estos individuales o colectivos, sino que es, más bien, un modo como ciertas acciones modifican otras. Lo anterior implica renunciar, por un lado, a la idea de un sujeto fundante, preexistente, $\mathrm{y}$, por el otro, prescindir de toda concepción de algo llamado Poder, cuya existencia per se, se puede postular en términos universales y abstractos.

El poder, por ende, solamente existe cuando es puesto en acción, cuando actúa, cuando opera sobre otras acciones, generalmente sobre las acciones de los otros. Las relaciones de poder, por consiguiente, se inscriben en un campo relacional dinámico y cambiante, configurado por respuestas, réplicas, reacciones, refutaciones, antagonismos, resultados y posibles invenciones.

Hay, por supuesto, al interior de estos entramados múltiples y plásticos de relaciones de poder, determinados puntos ciegos, resistentes a las afecciones por parte de los poderes operantes. Dichos puntos de resistencia, lejos de conformar un problema para el establecimiento de las relaciones de poder - tal como sucede en la doctrina pulsional freudiana- son absoluta e irrenunciablemente fundamentales para la existencia de éstas, pues no sería posible, para las relaciones de poder, existir sin dichos puntos de indocilidad e insubordinación 


\section{Acerca de la función emancipatoria y el estatuto crítico de la interpretación}

Hay efectos activos y reactivos. Los primeros son del orden de incitar, suscitar, producir, obligar; los segundos, de ser incitado, ser suscitado, ser obligado a producir. Los segundos no son el reverso de los primeros, sino el opuesto irreductible, en tanto y en cuanto la fuerza afectada tiene capacidad de resistencia (Díaz, 1992:102)

Micropolítica del poder y ética de la interpretación se anudan en torno al concepto de inconsciente, propuesto en su momento por Freud y recuperado por Lacan ante el peligro de su caída en el olvido. La resistencia, propiamente tal, se vincula al descubrimiento de lo inconsciente y a su inscripción en la memoria del psicoanálisis. El hallazgo de lo inconsciente constituyó un antecedente histórico inolvidable, cuya huella aún se conserva viva en los archivos del psicoanálisis y que exitosamente se sustrae a todos los intentos de domesticación por parte de los discursos normativos y adaptacionistas. A pesar de las diferentes lecturas de Freud, empecinadas en borrar el rastro de lo inconsciente de los textos psicoanalíticos oficiales o, al menos, de desfigurarlo hasta la irreconocibilidad, su trazo singular se mantiene inerte a semejantes intentos de asimilación.

El carácter único e inconfundible del psicoanálisis reside, precisamente, en este núcleo hermético e inasimilable: punto enigmático en el cual todos los señalamientos significantes apuntan al vacío. De manera paradojal, el psicoanálisis —en lugar de asentarse sobre firmes bases epistemológicas - se apuntala en un punto evanescente y fugaz, condición epistemológica que lo predispone para el ejercicio de la crítica.

Este punto evanescente, ubicado en los límites internos del propio psicoanálisis, hace de causa y fin del discurso psicoanalítico, es, si se prefiere, un punto imposible. En consecuencia, los esfuerzos interpretativos, que apuntan al esclarecimiento del sentido de los síntomas psíquicos - tal como ya advertía Freud en La interpretación de los sueños (1899-1900) - siempre son y serán una interpretación incompleta, una interpretación en falta y ello, principalmente, por dos razones. Su incompletitud fundamental se debe, en primer lugar, a la evidente multivocidad de los síntomas neuróticos, su estratificada y, a veces, heterogénea composición por diversas capas (Vielschichtigkeit) que condensan y reúnen varios cumplimientos de deseo a la vez, a ratos contradictorios e inconciliables entre sí. Es así como S. Freud, ya en la primera edición de su libro sobre los sueños, señalaba "que en rigor nunca se está seguro de haber interpretado un sueño exhaustivamente; aun cuando parece que la resolución es satisfactoria y sin lagunas, sigue abierta la posibilidad de que a través de ese mismo sueño se haya insinuado otro sentido" (Freud, 1900-1899:287). 


\section{Niklas Bornhauser}

Por lo tanto, mediante el trabajo interpretativo siempre se producen nuevas significaciones que, sin embargo, resultan insuficientes para agotar el sentido de un texto plástico, prolífico y exuberante en significaciones. En otras palabras, el añorado encuentro con el "verdadero" sentido, la extracción de la verdad última y definitiva, es, en realidad, un momento ideal, siempre postergado, siempre por venir.

No obstante, existe una segunda razón, quizá incluso más fundamental, que impide que se realice la interpretación íntegra y exhaustiva y que se produzca la clausura definitiva del sentido. Este segundo argumento en contra de la posibilidad de la generación de una interpretación "total” — sin restos ni residuos a interpretar, asimismo se encuentra en el texto princeps freudiano, responsable de la apertura de la vía regia hacia lo inconsciente - arranca de la consideración de un elemento destacado al interior del denso tejido onírico, en palabras de Freud, "un lugar en el cual es insondable, un ombligo por el que se conecta con lo no conocido” (1900:132-18).

Es decir, la interpretación, que hasta este momento avanzaba firme e imperturbablemente con su tarea de análisis, de déliaison o Auflösung, se topa de imprevisto con algo que se resiste a ser interpretado, un punto en el cual se muestran y entremezclan "todas las significaciones de equivalencia, todas las condensaciones que (uno) pueda imaginar” (Lacan, 1983:188). Madeja de procesos primarios, lioso entrelazamiento de encadenamientos significantes, anudamiento, enlace o ligadura (Verknüpfung) imposible de disolver. Es en esta desgarradura del tejido del lenguaje donde se produce el (des)encuentro con lo Unerkannte, lo no-(re)conocido e innombrable, en torno al cual se umbilican las cadenas significantes que, ocultándolo, lo protegen para mantenerlo en su estatuto de causa del discurso.

En este punto, imposible de conocer que remite a lo reprimido primordial (das Unverdrängte) a lo indecible indecible, y que, por ello mismo -empleando una expresión de Lacan, "no cesa de no escribirse” (Lacan, 1975) - se sostiene el discurso freudiano. De esta manera, en cada texto, por mucho que el intérprete se empeñe en tornar inteligibles hasta sus elementos más nimios, más insignificantes, hay un topos inaccesible, que ya no —como en caso de la condensación - se presenta como una frontera provisoria, una limitación temporal y pasajera, sino como "la noche más oscura", lo desconocido impenetrable, absoluto y originario. En este lugar imposible se manifiesta una entidad positiva que dista de ser el simple negativo de la conciencia, sino que sólo obtiene su consistencia sobre la base de un no-saber determinado. En otras palabras, la condición ontológica positiva del psicoanálisis depende, precisamente, de que algo permanezca no-simbolizado, que algo se sustraiga a la capacidad sistematizadora del lenguaje. 
El omphalos del sueño, por lo tanto, se presenta como la más absoluta oscuridad, como el reverso del relato del sueño; un punto ciego, imposible de enfocar mediante la interpretación. No obstante, el ombligo del sueño, a modo de ejemplo, no es un más allá de, un jenseits, sino una mancha o un lugar vacío inherente al texto simbólico que distorsiona y altera la percepción de la realidad. Lejos de situarse en la más absoluta exterioridad del lenguaje, en un más allá trascendental, le pertenece íntimamente a lo Simbólico conformando su delimitación interna. El umbilicamiento de los significantes, su anudamiento en la figura del ombligo, al servir de pivote de lo Simbólico, asegura la existencia de la distinción entre lo interior y lo exterior; sostiene la frontera divisoria entre adentro y afuera.

Por lo tanto, la función de aquel residuo no-interpretable consiste precisamente en impedir que en el plano del lenguaje se produzca la identidad consigo mismo, es decir, que el orden simbólico "retorne a sí mismo". Aquella discrepancia irreducible, ese resto imposible de decir, sería entonces lo que nos constituye como parlêtres y que, como consecuencia, nos permite y nos hace hablar.

Esta particularidad del campo simbólico —a saber, que éste en sí siempre ya está agujereado, coartado, lisiado, estructurado en torno a un núcleo éxtimo, una imposibilidad lógica, con respecto a la relación del sujeto con el lenguaje - significa que "el alcance del sentido", lejos de circunscribirse a una transcripción literal, palabra por palabra, del discurso del sueño, "desborda infinitamente los signos manipulados por el individuo" (Lacan, 1983:188). Hay siempre un plus-de-sentido, un exceso simbólico, límite ultimativo del proceso psicoanalítico, frontera infranqueable que viene dada por la naturaleza del comprender hermenéutico.

Es posible pensar que el encuentro freudiano con aquel punto decisivo, en el cual se produce la revelación de lo Real en lo que tiene de menos transparente, de lo Real sin mediación simbólica alguna, de lo Real último, ante lo cual las palabras se detienen y todas las categorías del lenguaje fracasan — si bien atraviesa toda su obra - puede ser localizado con particular nitidez en escritos como Die Traumdeutung (1899-1900) Das Unheimliche (1919) y Jenseits des Lustprinzips (1920). Es en estos textos, en los mismos límites del psicoanálisis, en los cuales se inicia el giro decisivo del psicoanálisis —que es, en cierto sentido, una inversión desde las ciencias naturales, su método, sus procedimientos, sus regulaciones y sus idealeshacia aquel tipo de razonamiento más emparentado con la literatura, la poesía, la mitología y la filosofía. Sin la notable sensibilidad de Freud hacia las inflexiones del lenguaje, su interés por el estudio sistemático de sus vuelcos y sus torsiones, el psicoanálisis, tal como se presenta hoy en día, no habría llegado a conformarse (Braunstein, 1982). La obra freudiana, en tanto práctica 


\section{Niklas Bornhauser}

escritural, constituye el testimonio de su encuentro dislocador con lo innombrable.

Al mismo tiempo, los textos freudianos, leídos en perspectiva, dan cuenta de la inauguración de una relación completamente nueva y diferente al lenguaje. En ellos se anticipa, discute y elabora la sustitución de la mirada médica por la escucha psicoanalítica; un giro que significó, a su vez, un vuelco decisivo para la comprensión y el tratamiento de las formaciones psíquicas contemporáneas. Al estar entregado al lenguaje, el sujeto no está expuesto ni a la plenitud ni al vacío del ser, sino que se mueve en un extraño entremezclamiento de los dos. Siempre queda un resto inexplicable, un residuo, que no se sigue de una eventual insuficiencia de sus posibilidades explicativas, sino que es constitutivo para que siquiera pueda desear y conocer. Este resto, presente como algo radicalmente in-nombrado, indeterminado, a-conceptual, es lo propiamente inconsciente.

El énfasis freudiano en los vacíos, las omisiones y ausencias; las contradicciones y repeticiones indeseadas; el lapsus, el error y la química de las sílabas, subraya la estrecha vinculación entre la estructura de lenguaje e inconsciente. El surgimiento repentino de lo ominoso, el asalto de lo críptico e indescifrable, de aquello que insistentemente se resiste a ser interpretado, es uno de los antecedentes más relevantes al momento de considerar lo inconsciente y los límites de la interpretación psicoanalítica y, con ello, de definir su posición con respecto al postulado de que no hay ejercicio de poder posible sin una cierta economía de los discursos de verdad que funcionen en y a partir de esta pareja.

Producción de la verdad y relaciones de poder se articulan, por lo tanto, en un doble sentido: en primer lugar, toda producción de verdad está sometida al poder y, en segundo lugar, el poder no puede ejercitarse sino a través de la producción de la verdad.

La tarea del psicoanálisis como crítica, en ese sentido, por un lado consiste en contribuir a mostrar cómo el saber y el poder operan para constituir un modo más o menos sistemático de ordenar el mundo con sus propias condiciones de aceptabilidad, pero, por el otro, en estar atento a las grietas, las fisuras y los puntos de ruptura en los cuales se asoman formas alternativas, cualitativamente diferentes, de pensar. Lo anterior significa que se deben buscar tanto las condiciones mediante las cuales el campo es constituido e instituido, así como los confines de esas condiciones, los momentos cuando esos límites señalan su contingencia y su transformabilidad.

La crítica psicoanalítica, consiguientemente, presenta ciertas afinidades con "el arte de la inservidumbre voluntaria, de la indocilidad reflexionada (l'indocilité réfléchie)” y "tendría esencialmente como función la desujeción 
(désassujettissement) en el juego de lo que se podría denominar, con una palabra, la política de la verdad” (Foucault, 2006:11).

En la medida en que las relaciones de poder emplazadas y los saberes instaurados se materializan y consolidan en determinadas formas del pensar, avaladas por los correspondientes aparatos ideológicos de Estado, la práctica crítica debe enfrentar una doble tarea: en primer lugar, develar las relaciones de poder materializadas, por ejemplo, en determinados aparatos ideológicos de estado, determinadas relaciones de dominio $^{3}$ o determinadas prácticas, establecidas, al parecer, de manera inapelable; segundo, hacerse cargo del desafío de esbozar las posibilidades de pensar de otra manera.

$\mathrm{Y}$ en esto, de acuerdo con lo expuesto, consiste el genuino potencial crítico del psicoanálisis: en su defensa y rescate del ethos griego que consiste, precisamente, en recuperar la posibilidad de pensar de una manera cualitativamente diferente. La realización de esta posibilidad pasa, en primer lugar, por la rotunda y categórica recusación del pensamiento único y totalizador y, en segundo lugar, por la reformulación de sus principios y de sus ideales (de cura, de adaptación, de salud mental) desenmascarando, de este modo, la ironía de aquellos dispositivos de saber y poder que elaboran, sostienen y fomentan determinados modos de sujeción enmascarados bajo las promesas de liberación terapéutica.

Del desenlace de sus esfuerzos por aspirar a lograr lo anterior, lo que supone problematizar y administrar las relaciones de poder en cuyo entramado se inscribe dicho enfrentamiento, dependen no solamente sus posibilidades de diálogo y de debate con otras prácticas discursivas, sino quizá, incluso, el devenir de un proyecto múltiple y plural, auténticamente crítico y emancipatorio, tal como lo es el psicoanálisis en su concepción freudiana.

\footnotetext{
${ }^{3}$ El análisis del problema del poder, tal como ha advertido M. Foucault, suele encontrarse con una serie de obstáculos. Entre ellos, la tendencia a reducir toda la discusión a un problema de soberanía o a concebir el poder de manera exclusivamente negativa, represiva y restrictiva. El poder, más bien, se construye y funciona a partir de otros poderes, de los efectos de éstos, conformando y potenciándose a partir de la consolidación de una red filigrana y pormenorizada de producción (Foucault, 1999a). Asimismo, el poder — en estricto rigor- nunca se posee, sino que funciona, se ejerce o ejercita a través de organizaciones reticulares, conformadas por puntos de ensambladura y de conexión, por las que transita incesante y permanentemente. De este modo, el poder ha de ser separado de todo fenómeno de dominación masiva y homogénea, ejercido a lo largo del tiempo por un individuo, un grupo o una clase sobre los otros. La dominación, en este sentido, es una estructuración general y relativamente estable de poder, presentada en términos de lucha-sumisión, mientras que éste se caracteriza por su esencial movilidad y productividad (Foucault, 1999b).
} 
Niklas Bornhauser

\author{
Universidad Andres Bello* \\ Facultad de Ciencias Sociales \\ Escuela de Psicología \\ Av. Fernández Concha 700, Las Condes, Santiago (Chile) \\ nbornhauser@unab.cl
}

\title{
BIBLIOGRAFÍA
}

ADORNO, Theodor. W. Prismen, Kulturkritik und Gesellschaft. Frankfurt a. M.: Suhrkamp, 1969.

BARTHES, Roland. L'obvie et l'obtus: Essais critiques III. Paris: Seuil, 1982. BERCHERIE, Paul. Genèse des concepts freudiens. Paris: Navarin, 1983.

BRAUNSTEIN, Néstor (Ed.). El lenguaje y el inconsciente freudiano. México: Siglo XXI, 1982.

BUTLER, Judith. "What Is Critique? An Essay on Foucault's Virtue", en Ingram, Dave (ed.) The Political. Readings in Continental Philosophy. London: Basil Blackwell, 2002.

DELEUZE, Gilles. "Les intellectuels et le pouvoir. Entretien entre Michel Foucault et Gilles Deleuze”, en L'Arc 49 (1972):13-19.

DÍAZ, Esther. Michel Foucault, los modos de subjetivación. Buenos Aires, Almagesto, 1992.

EWALD, François. "Un pouvoir sans dehors", en Michel Foucault, philosophe. Paris: Seuil (1989):196-202.

FIGUEROA, Gustavo. "Freud 150 años: Maestro de la sospecha”, en Revista Chilena de Neuro-Psiquiatría 45 (2007):16-17.

FORSTER, Ricardo. "Tradición crítica y Escuela de Frankfurt”, en Casullo, Nicolás; Forster, Ricardo y Kaufman, Alejandro. Itinerarios de la Modernidad. Buenos Aires: Eudeba, 1999.

FOUCAULT, Michel. “¿Qué es la crítica? (Crítica y Aufklärung)”, en Sobre la Ilustración. Madrid: Tecnos (2006):3-52.

------- "Los intelectuales y el poder", en Estrategias de poder. Obras esenciales. Vol. II. Barcelona: Paidós, 1999a.

------- “Las mallas del poder”, en Estética, ética y hermenéutica. Obras esenciales. Vol. III. Barcelona: Paidós, 1999b.

“De la arqueología a la dinástica”, en Estrategias de poder. Barcelona: Paidós, 1999.

------ "El sujeto y el poder”, en Dreyfus, Hubert y Rabinow, Paul. Michel Foucault: más allá del estructuralismo y la hermenéutica. México: Universidad Nacional Autónoma de México (1988):227-244.

Nietzsche, Freud, Marx. Buenos Aires: El cielo por asalto, 1995. 
Acerca de la función emancipatoria y el estatuto crítico de la interpretación

FREUD, Sigmund. "La interpretación de los sueños (1900-1899)”, en Obras Completas. Vol. IV. Buenos Aires: Amorrortu, 1992.

"Pulsiones y destinos de pulsión (1915)", en Obras Completas. Vol. XIV. Buenos Aires: Amorrortu, 1989.

FRIEDEBURG, Ludwig von; HABERMAS, Jürgen (Eds.). Adorno-Konferenz Frankfurt am Main: Suhrkamp, 1983.

GRAMSCI, Antonio. Introducción a la filosofía de la praxis. Barcelona, Península, 1972.

GRUBRICH-SIMITIS, Ilse. Zurück zu Freuds Texten. Stumme Dokumente sprechen machen. Frankfurt am Main: S. Fischer, 1993.

GRÜNER, Eduardo. "Foucault: una política de la interpretación”, en Michel Foucault. Nietzsche, Freud, Marx. Buenos Aires: El cielo por asalto, 1995.

GUMBRECHT, Hans-Ulrich. Dimension und Grenzen der Begriffsgeschichte. Paderborn: Wilhelm Fink Verlag, 2006.

HABERMAS, Jürgen. Erkenntnis und Interesse. Frankfurt am Main: Suhrkamp, 1968.

JAY, Martin. The Dialectical Imagination: A History of the Frankfurt School and the Institute of Social Research, 1923-50. London: Heinemann, 1973.

KANT, Immanuel. "Beantwortung der Frage: Was ist Aufklärung?” (1784). Ausgewählte kleine Schriften. Hamburg: Felix Meiner (1965):1-9.

KOSELLECK, Reinhart (Ed.). Historische Semantik und Begriffsgeschichte. Stuttgart: Klett-Cotta, 1979.

KUHN, Thomas. The Structure of Scientific Revolutions. Chicago: University of Chicago Press, 1970.

LACAN, Jacques. Le Séminaire VIII. Le transfert (1960-61). Paris: Seuil, 1991.

------- Seminario 2. El Yo en la Teoría de Freud y en la Técnica Psicoanalítica (1954-1955). Buenos Aires: Paidós, 1983.

------ Le Séminaire XX. Encore. (1972-73). Paris: Seuil, 1975.

------- "Función y campo de la palabra y del lenguaje en psicoanálisis", en Escritos I. México: Siglo Veintiuno, 1972.

LYOTARD, Jean-François. La condition postmoderne. Paris: Minuit, 1979.

MAHONY, Patrick. Freud as a Writer. New York: International Universities Press, 1982.

MARCUSE, Herbert. One Dimensional Man. Boston: Beacon Press, 1964.

MCCARTHY, Thomas. The Critical Theory of Jürgen Habermas. London: Hutchinson, 1978.

MILMANIENE, José E. Clínica del texto. Kafka, Benjamin, Lévinas. Buenos Aires: Biblos, 2002. 
Niklas Bornhauser

PASTERNAC, Marcelo. "El método psicoanalítico”, en Néstor Braunstein (ed.) Psicología: ciencia e ideología. México: Siglo XXI, 1975.

POHLEN, Manfred; BAUTZ-HOLZHERR, Margarete. Eine andere Aufklärung. Das Freudsche Subjekt in der Analyse. Suhrkamp. Frankfurt am Main, 2001.

RICOEUR, Paul. "La psychanalyse et le mouvement de la culture contemporaine”, en Le conflit des interprétations. Essais d'herméneutique. Paris: Seuil, 1969.

------- De l'interprétation. Essai sur Freud. Paris: Seuil, 1965.

ROZITCHNER, Leon. Freud y los límites del individualismo burgués, $3^{\mathrm{a}}$ edición. México: Siglo XXI, 1987.

WIGGERSHAUS, Rolf: Die Frankfurter Schule. Geschichte-Theoretische Entwicklung-politische Bedeutung. München/Wien: Carl Hanser Verlag, 1986.

WILLIAMS, Raymond. Keywords: a vocabulary of culture and society. Glasgow: Collins, 1976. 